\title{
Identification of the major yeasts isolated from high moisture corn and corn silages in the United States using genetic and biochemical methods
}

\author{
M. C. Santos, ${ }^{*}$ C. Golt,† R. D. Joerger, ${ }^{*}$ G. D. Mechor,‡ Gerson B. Mourão,§ and L. Kung Jr. ${ }^{* 1}$ \\ *Department of Animal and Food Sciences, and \\ †Department of Plant and Soil Sciences, University of Delaware, Newark 19716 \\ ‡Elanco Animal Health, Greenfield, IN 46140 \\ $\S$ Department of Animal Science, University of São Paulo, Piracicaba, SP 13418-900, Brazil
}

\section{ABSTRACT}

The objective of this study was to identify species of yeasts in samples of high moisture corn (HMC) and corn silage (CS) collected from farms throughout the United States. Samples were plated and colonies were isolated for identification using DNA analysis. Randomly selected colonies were also identified by fatty acid methyl esters (FAME) and by physiological substrate profiling (ID 32C). For CS, Candida ethanolica, Saccharomyces bulderi, Pichia anomala, Kazachstania unispora, and Saccharomyces cerevisiae were the predominant yeasts. Pichia anomala, Issatchenkia orientalis, S. cerevisiae, and Pichia fermentans were the prevalent species in HMC. The 3 identification methods were in agreement at the species level for $16.6 \%$ of the isolates and showed no agreement for $25.7 \%$. Agreement in species identification between ID $32 \mathrm{C}$ and DNA analysis, FAME and ID $32 \mathrm{C}$, and FAME and DNA analysis was 41.1, 14.4, and $2.2 \%$, respectively. Pichia anomala and I. orientalis were able to grow on lactic acid, whereas $S$. cerevisiae metabolized sugars (galactose, sucrose, and glucose) but failed to use lactic acid. The yeast diversity in CS and HMC varied due to type of feed and location. Differences in species assignments were seen among methods, but identification using substrate profiling generally corresponded with that based on DNA analysis. These findings provide information about the species that may be expected in silages, and this knowledge may lead to interventions that control unwanted yeasts. Key words: fermentation, Pichia anomala, spoilage

\section{INTRODUCTION}

Anaerobic fermentation and aerobic spoilage by yeasts are undesirable in silage. Yeasts tend to grow best aerobically but can ferment sugars anaerobically

Received May 12, 2016.

Accepted October 2, 2016.

${ }^{1}$ Corresponding author: lksilage@udel.edu and produce ethanol and $\mathrm{CO}_{2}$ when trace amounts of oxygen are present, resulting in large losses of DM (McDonald et al., 1991). The degree of anaerobiosis during storage and the concentration of organic acids are important factors that affect the survival of yeasts. Jonsson and Pahlow (1984) reported that the presence of oxygen enhanced survival and growth of yeasts, whereas a high level of acetic acid reduced their viability during storage.

When silage is exposed to air, during feed-out in the silo or in the feed bunk, aerobic microorganisms can become active. It is generally accepted that yeasts play a major role in initiating aerobic spoilage of silage (Jonsson and Pahlow, 1984). Under aerobic conditions, spoilage yeasts are able to oxidize sugars and lactic acid, resulting in the production of $\mathrm{CO}_{2}, \mathrm{H}_{2} \mathrm{O}$, and heat, and thus causing spoilage (Woolford, 1990) and loss of important nutritional components (Kung et al., 1998). The degradation of lactic acid by yeasts causes a rise in silage $\mathrm{pH}$ to a level that allows opportunistic bacteria (e.g., bacilli) and molds (e.g., Aspergillus, Fusarium, and Penicillium) to grow and further reduce silage quality (McDonald et al., 1991).

The population of yeasts associated with aerobic spoilage of silages can be divided into 2 physiological groups. The first group is composed of yeasts with a high ability to ferment sugars but varying ability to assimilate lactic acid. These organisms include Saccharomyces cerevisiae and species of Torulopsis. The second group is composed of yeasts that have a high respiratory affinity for lactic acid. These organisms include species of Candida, Issatchenkia, Pichia, Hansenula, and Endomycopsis (Moon and Ely, 1979; Jonsson and Pahlow, 1984; McDonald et al., 1991). Pahlow et al. (2003) reported that yeasts of the genera Candida and Hansenula (Pichia) are particularly prolific during the aerobic phase of silage spoilage because of their lactateassimilating ability and their strong affinity for glucose.

Plating silage extracts on solid agar medium yields the number of culturable colony-forming units per gram of fresh material that appear on a particular me- 
dium at a given temperature. The colonies can then be studied with different methods to determine the species of yeast (Querol and Ramòn, 1996). Classical or traditional microbiological procedures are based on microbial culturing, and macroscopic and microscopic analysis of colonies and cells or phenotypic traits such as fermentation products and enzyme activity. In recent years, rapid identification methods have been developed to overcome the complexity of traditional yeast identification methods. These methods are based on substrate assimilation and are characterized by the development of growth of an organism in the presence of chemically pure substrates. The analytical profile index (API) 20C system (bioMérieux, Marcy-l'Etoile, France; Buesching et al., 1979) is considered a reliable and proven system (Willemsen et al., 1997; Heelan et al., 1998) and has been a commonly used system for identification of yeasts. A similar identification system is the ID 32C (bioMérieux). The advantage of the ID $32 \mathrm{C}$ for the identification of yeasts in silage samples is the presence of lactic acid as a substrate for growth. The ID 32C has been used as a reference system due to its extensive database and accuracy (Gutierrez et al., 1994; Fricker-Hidalgo et al., 1995, 1996). Fatty acid methyl ester profiling of the cell wall is another method that can be used for the identification of microorganisms, including yeasts (Botha and Kock, 1993).

In the last decade, molecular methods have been developed for the identification of yeast (Chang et al., 2001; Luo and Mitchell, 2002). For species differentiation and to establish phylogenetic relationships, the most common method is sequencing of ribosomal DNA (Kurtzmann, 1992; Yamada et al., 1994; Cai et al., 1996). The approach consists of amplification of yeast rDNA sequences or the internal transcribed spacer (ITS) region by PCR, followed by sequencing of the resulting DNA products. Application of molecular approaches has had a considerable effect on species assignments and the shift to a genomic basis for species delineation caused the merger of physiological or morphological variants into larger and more diverse species (Lachance, 2006).

The type of yeasts and their metabolism in silage has not been well studied in corn silage (CS) or high moisture corn (HMC) in the United States. Thus, the aims of the present study were to identify and characterize the major species of yeasts associated with samples of CS and HMC collected from dairy farms throughout the United States. Yeast identification was conducted by sequencing of the ITS region of the DNA, FAME analysis of the cell wall, and physiological substrate profiling, and the results obtained by these methods were compared.

\section{MATERIALS AND METHODS}

\section{Sample Collection and Preparation}

Ten CS and 11 HMC samples from dairy farms located in 9 states (New York, Idaho, Ohio, Washington, West Virginia, Michigan, Iowa, Minnesota, and Wisconsin) were used for the isolation and characterization of yeasts associated with silages. Silages were stored in a variety of silo types between 7 and 11 mo and sampled directly from the silos. The samples were characterized as having "high" populations of yeasts as described by a nutritionist or technical service representative servicing the farm. Samples were immediately shipped on ice via expedited delivery services to the University of Delaware. Upon arrival, water extracts of the samples were prepared by blending $25 \mathrm{~g}$ of silage with $225 \mathrm{~mL}$ of sterile quarter-strength Ringers solution (Oxoid BR52, Unipath, Basingstoke, UK) for $1 \mathrm{~min}$ in a Proctor-Silex 57171 blender (Hamilton Beach/Proctor-Silex Inc., Washington, NC). Silage pH was measured and a portion of the water extract was filtered through Whatman 54 filter paper (Whatman, Florham, NJ), acidified with $50 \% \mathrm{H}_{2} \mathrm{SO}_{4}$, and frozen before analysis of their lactic acid, acetic acid, and ethanol contents, using HPLC (Muck and Dickerson, 1988). The HPLC system consisted of a Shimadzu system controller (CBM-20A), pump (LC-20AT), and refractive index detector (RID10A, Shimadzu Corporation, Kyoto, Japan) with a BioRad Aminex HPX-87H ion exchange column (300 mm $\times 7.8 \mathrm{~mm}$ i.d., Bio-Rad Laboratories, Hercules, CA) heated to $35^{\circ} \mathrm{C}$ and with a mobile phase composed of $7.5 \mathrm{mM} \mathrm{H} \mathrm{H}_{2} \mathrm{SO}_{4}$ plus $0.25 \mathrm{~m} M$ EDTA at $0.6 \mathrm{~mL} / \mathrm{min}$. A portion of each sample was dried in a forced-draft oven at $60^{\circ} \mathrm{C}$ for $48 \mathrm{~h}$ for the determination of DM content.

\section{Enumeration and Isolation of Yeasts}

A portion of the silage water extract was filtered through a double layer of sterile cheesecloth and $1 \mathrm{~mL}$ was 10-fold serially diluted for enumeration of yeasts and molds on pour-plates containing malt extract agar (Oxoid CM59, Unipath) acidified with $85 \%$ lactic acid at a rate of $0.5 \% \mathrm{vol} / \mathrm{vol}$. After incubation at $32^{\circ} \mathrm{C}$ for 48 to $72 \mathrm{~h}$, colonies were enumerated and all microbial counts were transformed to $\log _{10} \mathrm{cfu} / \mathrm{g}$ and expressed on a fresh weight basis. Between 15 to $20 \%$ of the yeast colonies were randomly picked from the Petri dish at the highest dilution and containing $>30$ colonies. The colonies were streaked onto Sabouraud dextrose agar (Becton Dickinson, Sparks, MD), grown at $28^{\circ} \mathrm{C}$ for 24 to $48 \mathrm{~h}$, and a single colony-forming unit was recovered. The colony purification process was repeated 2 more 
times, and a colony-forming unit was picked, stored in $15 \%$ glycerol solution, and frozen at $-80^{\circ} \mathrm{C}$.

\section{DNA Extraction and Gene Sequencing}

Colonies were grown from the frozen cultures on Sabouraud dextrose agar and incubated at $28^{\circ} \mathrm{C}$ for 24 to $48 \mathrm{~h}$. Two $4-\mathrm{mm}$ loopfuls of yeast cells from the Petri dishes were added to a sterile 2.0-mL screw-cap conical tube containing $0.5 \mathrm{~g}$ of $0.1-\mathrm{mm}$ diameter zirconia/silica beads (Biospec Products Inc., Bartlesville, $\mathrm{OK})$ and $800 \mu \mathrm{L}$ of TE buffer $(10 \mathrm{~m} M$ Tris-HCl, $1 \mathrm{mM}$ EDTA, pH 8.0). The samples were homogenized for 2 min on a minibead beater (Biospec Products Inc.) at maximum speed. The PCR reaction was carried out in $50-\mu \mathrm{L}$ volumes with $4 \mu \mathrm{L}$ of the homogenate, $0.5 \mu \mathrm{L}$ of each primer at a final concentration of $1 \mu M, 20 \mu \mathrm{L}$ of water, and $25 \mu \mathrm{L}$ of $2 \times$ GoTaq Green Master Mix (Promega, Madison, WI). The fungus-specific universal primers ITS1 (5'-TCCGTAGGTGAACCTGCGG-3') and ITS4 (5'-TCCTCCGCTTATTGATATGC-3') were used for PCR amplification (White et al., 1990). All reactions were carried out in Robocycler Gradient 96 Temperature Cycler (Stratagene, La Jolla, CA) under the following conditions: an initial denaturation for 2 min at $94^{\circ} \mathrm{C}$ and 30 amplification cycles of denaturation $\left(94^{\circ} \mathrm{C}\right.$ for $\left.1 \mathrm{~min}\right)$, annealing $\left(60^{\circ} \mathrm{C}\right.$ for $\left.1 \mathrm{~min}\right)$, and extension $\left(72^{\circ} \mathrm{C}\right.$ for $\left.1 \mathrm{~min}\right)$. The PCR products were purified using the QIAquick PCR purification kit (Qiagen, Hilden, Germany) and quantified using a Nanodrop ND-1000 spectrophotometer (Nanodrop Technologies, Wilmington, DE) before sequence determination at the University of Delaware DNA sequencing core facility. Sequencing reactions were performed with a PE-ABI Big Dye Terminator cycle sequencing kit (Applied Biosystems, Foster City, CA) as described by the manufacturer, and electrophoresis and readout were done with an ABI PRISM 3130 XL DNA analyzer (Applied Biosystems). Primers ITS1 and ITS4 were used as sequencing primers and the resulting sequences were compared using nucleotide-nucleotide BLAST (blastn), and species identification was determined from the lowest e-value of the BLAST output. Sequences longer than $200 \mathrm{bp}$ were submitted to GenBank and are accessible under accession numbers KM374062 to KM374304.

\section{FAME Analysis}

Ninety random colonies were prepared for FAME analysis according to the protocol recommended by Sasser (1991). Approximately $40 \mathrm{mg}$ of yeast biomass was placed in the bottom of a sterile screw-cap tube $(13 \times 100 \mathrm{~mm})$. The cells were lysed, and fatty acids were saponified by the addition of $1.0 \mathrm{~mL}$ of a solution containing sodium hydroxide $15 \% \mathrm{wt} / \mathrm{vol}$ in aqueous methanol $50 \% \mathrm{vol} / \mathrm{vol}$ and heated at $100^{\circ} \mathrm{C}$ in a water bath for $5 \mathrm{~min}$. Tubes were vigorously vortexed for 5 to $10 \mathrm{~s}$ and returned to the water bath for an additional 25 min. The fatty acids were converted to fatty acid methyl esters by addition of $2.0 \mathrm{~mL}$ of a solution containing 6 $M$ hydrochloric acid and methanol (1:0.85 ratio) and heated at $80^{\circ} \mathrm{C}$ for $10 \mathrm{~min}$. Fatty acid methyl esters were extracted from the aqueous phase with $1.25 \mathrm{~mL}$ of hexane-methyl-tert-butyl ether reagent (1:1). After extraction, $3 \mathrm{~mL}$ of a solution of sodium hydroxide $(0.3$ $M$ ) was used to remove free fatty acids and residual reagents from the organic extracts. Finally, the upper organic phase was removed and injected into a gas chromatographic system (Hewlett Packard Co., Avondale, PA), consisting of a model 5890 Series II Plus gas chromatograph, equipped with a $5 \%$ phenylmethyl silicone capillary column (Hewlett Packard Co., Ultra $2,25 \mathrm{~m} \times 0.2 \mathrm{~mm} \times 0.33 \mu \mathrm{m})$, a split/splitless capillary inlet system, a flame ionization detector, and a model 6890 injector with automatic sample. The temperature program gradually increased from 170 to $270^{\circ} \mathrm{C}$ at a rate of $5^{\circ} \mathrm{C} / \mathrm{min}$. The output from the chromatograph was fed to an integrator for calculation of peak retention times and areas, and the data were transferred to a computer for peak identification and comparison of the profile with reference profile libraries (MIDI; Sherlock 4.5 Microbial Identification System, Newark, DE).

\section{API 32C System}

The API kit ID 32 C (bioMérieux) was used for physiological substrate profiling. This system consisted of a single-use disposable plastic strip with 32 wells containing substrates for 29 assimilation tests (carbohydrates, organic acids, and AA), one susceptibility test (cycloheximide), one colorimetric test (esculin), and a negative control. The yeast identification procedures were conducted in accordance with the manufacturer's instructions. Briefly, cells from well-isolated colonies were aseptically transferred to sterile distilled water to prepare a suspension with a final turbidity equivalent to McFarland standard \#2. Subsequently, $250 \mu \mathrm{L}$ of this suspension was dispensed into an ampule of ID $32 \mathrm{C}$ medium provided by the manufacturer, mixed, and used to inoculate the wells of the strip. The lid of the strip was replaced, and the strips were incubated at $30^{\circ} \mathrm{C}$ for $48 \mathrm{~h}$. Growth was determined to be positive or negative based on the presence or absence of turbidity in the wells. The results were transformed into numerical biocodes, and the isolates were identified through the use of the software api-web 2006 (AB bioMérieux). 


\section{Statistical Analysis}

The experiment was analyzed as a complete randomized design. Data were analyzed utilizing the theory of generalized linear models (PROC GLIMMIX version 9.3, SAS Institute Inc., Cary, NC). For DM, lactic and acetic acid, ethanol, ratio of lactic to acetic acid and microbial counts, the model was adjusted using the generalized logit-link function and considering a $\beta$ distribution of the data. For $\mathrm{pH}$, identity was used as a link function and a normal distribution was considered. The model included the fixed effects of silage type and the random residual effect. Due to the heterogeneous variance of the data, specific variances were used for analysis. Mean separation was done by least significant difference and was reported as least squares means plus standard error of the means in original scale and using the inverse link option for ease of interpretation. Statistical significance and trends were declared at $P$ $\leq 0.05$ and $P>0.05$ to $P \leq 0.10$, respectively. Data on yeast identification and distribution were explored using descriptive analysis.

\section{RESULTS}

\section{Chemical and Microbial Characteristics of the Silages}

The DM content, $\mathrm{pH}$, fermentation end products, and yeast and mold counts are reported in Table 1 . The DM content was lower for CS in comparison with HMC, with an average of 34.7 and $69.2 \%$, respectively. Similarly, silage $\mathrm{pH}$ was lower for CS, with an average of 3.8, whereas for HMC the average $\mathrm{pH}$ was 4.3 . With regard to fermentation end products, CS had higher concentrations of lactic acid and acetic acid than HMC, with averages of 5.8 and 2.3 for CS and 1.1 and $0.4 \%$ of $\mathrm{DM}$ for $\mathrm{HMC}$, respectively. Also, a trend was present for higher concentration of ethanol in CS, whereas the ratio of lactic to acetic acid was not affected by silage type. Conversely, numbers of yeasts and molds tended to be higher for HMC in comparison with CS. Yeast counts averaged 6.3 and $5.4 \log _{10} \mathrm{cfu} / \mathrm{g}$ of silage, whereas numbers of molds averaged 2.0 and $1.2 \log _{10}$ $\mathrm{cfu} / \mathrm{g}$ of silage for HMC and CS, respectively.

\section{Yeasts Identification and Comparison Among Methods}

The percentage distribution of yeast species in CS and HMC as determined by DNA analysis is shown in Table 2. A total of 20 species of yeasts were identified in the current study, with 15 species detected in CS and 14 species detected in HMC by DNA analysis. For CS, Candida ethanolica (21.2\%), Saccharomyces bulderi (17.6\%), Pichia anomala (10.0\%), Kazachstania unispora (9.6\%), and S. cerevisiae (8.0\%) were the most prevalent yeasts and represented $66.4 \%$ of the isolates. The remaining $33.6 \%$ was represented by 10 other species that were presented in frequencies $\leq 7.5 \%$. For HMC, P. anomala (32.5\%), Issatchenkia orientalis (22.4\%), S. cerevisiae (16.1\%), and Pichia fermentans (12.4\%) were the most prevalent species and represented $83.5 \%$ of the total. Ten other species represented the remaining $16.5 \%$ of the isolates.

The percentage distribution of yeasts for each sample of CS is shown in Figure 1. Candida ethanolica and $S$. bulderi were detected in 4 out of 10 samples, varying from 10 to $100 \%$ and from 15 to $75 \%$ of isolates from the samples, respectively. Pichia anomala and $S$. cerevisiae were found in only one sample at percentages of 100 and $80 \%$, respectively, whereas K. unispora was found in the 2 samples at percentages of 89 and $7 \%$. For the 10 minor species, I. orientalis was detected in 3 samples, whereas the remaining species were detected in only 1 or 2 of the 10 samples that were analyzed.

The percentage distribution of yeasts for each sample of HMC is shown in Figure 2. Pichia anomala was found in 7 out of 11 samples obtained from 6 different states and the percentages varied from $5 \%$ (in NY-9) to $85 \%$ (in MI-2 and IA-1). The other predominant yeast in HMC was I. orientalis, which was found in 6 out of 11 samples at 5 different locations with percentages varying from 15 (in MI-2) to $70 \%$ (in NY-8). Saccharomyces cerevisiae and $P$. fermentans were detected in 4 out of 11 samples, with percentages of 27 to $80 \%$ (for $S$. cerevisiae) and 7 to $100 \%$ (for P. fermentans). These species were predominant in HMC probably because they are highly competitive in limiting moisture envi-

Table 1. Mean values (SEM in parentheses) of DM content, $\mathrm{pH}$, fermentation end products (DM basis), lactic:acetic acid ratio, and numbers of yeasts and molds (wet basis) of silage samples collected at different locations in the United States

\begin{tabular}{lcrr}
\hline & \multicolumn{2}{c}{ Silage type $^{1}$} & \\
\cline { 2 - 3 } Item & CS & HMC & $P$-value \\
\hline DM $(\%)$ & $34.7(1.4)$ & $69.2(1.7)$ & $<0.01$ \\
pH & $3.8(0.06)$ & $4.3(0.10)$ & $<0.01$ \\
Lactic acid (\% of DM) & $5.8(0.57)$ & $1.1(0.23)$ & $<0.01$ \\
Acetic acid (\% of DM) & $2.3(0.69)$ & $0.4(0.10)$ & $<0.01$ \\
Ethanol (\% of DM) & $1.0(0.24)$ & $0.5(0.16)$ & 0.08 \\
LA ratio & $2.5(0.64)$ & $2.8(0.96)$ & 0.22 \\
Yeast (log $\log _{10}$ cfu/g of silage) & $5.4(0.32)$ & $6.3(0.37)$ & 0.06 \\
Molds ( $\log _{10}$ cfu/g of silage) & $1.2(0.49)$ & $2.0(0.38)$ & 0.07 \\
\hline
\end{tabular}

${ }^{1} \mathrm{CS}=$ corn silage; $\mathrm{HMC}=$ high moisture corn.

${ }^{2} \mathrm{LA}$ ratio $=$ lactic:acetic ratio. 
ronments. Of the 10 minor species identified, 9 were detected in only 1 of the 11 samples. Overall, for each sample analyzed, the number of species varied from 1 to 5 in both type of silages (Figures 1 and 2).

Table 3 shows the percentage of agreement among the 3 methods used for the identification of 90 colonies. The methods were in agreement for the identification of $16.6 \%$ of the isolates. The identification using the API kit ID $32 \mathrm{C}$ and DNA analysis showed the best correspondence as they were in agreement for $41.1 \%$ of the isolates. Fatty acid methyl ester and the API kit ID $32 \mathrm{C}$ were in agreement for the identification of $14.4 \%$, whereas agreement was poor between FAME and DNA analysis (only $2.2 \%$ of the isolates). The 3 methods did not agree on the identification of the remaining $25.7 \%$ of the isolates.

\section{Substrate Utilization Profile of the Isolates}

Table 4 shows the substrate utilization of the 3 prevalent species of yeasts identified by DNA and substrate profile. Pichia anomala isolates were physiologically versatile as they were capable of growing on galactose, sucrose, lactic acid, maltose, xylose, and glucose. Is-

Table 2. Percentage distribution and rank (in parentheses) of yeast species isolated from corn silage ${ }^{1}$ and high moisture $\operatorname{corn}^{2}$ samples as determined by DNA analysis

\begin{tabular}{lcc}
\hline & \multicolumn{2}{c}{ Silage type $^{3}$} \\
\cline { 2 - 3 } Species & $\mathrm{CS}$ & $\mathrm{HMC}$ \\
\hline Candida ethanolica (\%) & $21.2(1)$ & $\mathrm{ND}^{4}$ \\
Candida humilis (\%) & $1.6(11)$ & $\mathrm{ND}$ \\
Candida rugosa (\%) & $2.0(10)$ & $\mathrm{ND}$ \\
Issatchenkia orientalis (\%) & $4.9(9)$ & $22.4(2)$ \\
Kazachstania barnettii (\%) & $7.5(6)$ & $\mathrm{ND}$ \\
Kazachstania exigua (\%) & $1.5(12)$ & $\mathrm{ND}$ \\
Kazachstania unispora (\%) & $9.6(4)$ & $0.6(12)$ \\
Naumovozyma castellii (\%) & $\mathrm{ND}$ & $3.6(5)$ \\
Pichia anomala (\%) & $10.0(3)$ & $32.5(1)$ \\
Pichia deserticola $(\%)$ & $1.1(13)$ & $\mathrm{ND}$ \\
Pichia fermentans (\%) & $6.5(7)$ & $12.4(4)$ \\
Pichia manshurica (\%) & $6.3(8)$ & $1.9(8)$ \\
Pichia membranifaciens (\%) & $1.1(13)$ & $2.3(7)$ \\
Pichia sporocuriosa (\%) & $\mathrm{ND}$ & $0.8(11)$ \\
Rhodotorula mucilaginosa (\%) & $1.1(13)$ & $1.4(9)$ \\
Saccharomyces bulderi $(\%)$ & $17.6(2)$ & $1.3(10)$ \\
Saccharomyces cariocus (\%) & $\mathrm{ND}$ & $2.6(6)$ \\
Saccharomyces cerevisiae (\%) & $8.0(5)$ & $16.1(3)$ \\
Saccharomyces dairenensis (\%) & $\mathrm{ND}$ & $0.6(12)$ \\
Saccharomyces paradoxus (\%) & $\mathrm{ND}$ & $1.3(10)$ \\
\hline
\end{tabular}

\footnotetext{
${ }^{1} \mathrm{~A}$ total of 106 colonies were isolated from 10 samples. Numbers in parentheses indicate a rank of species for corn silage.

${ }^{2} \mathrm{~A}$ total of 142 colonies were isolated from 11 samples. Numbers in parentheses indicate a rank of species for high moisture corn.

${ }^{3} \mathrm{CS}=$ corn silage; HMC $=$ high moisture corn.

${ }^{4}$ Not detected.
}

satchenkia orientalis isolates were able to grow on lactic acid and maltose, and 3 isolates had also the ability to use galactose as a substrate for growth. Saccharomyces cerevisiae showed a high affinity for sugars (galactose, sucrose, and glucose), but failed to use lactic acid, xylose, and maltose.

\section{DISCUSSION}

Except for 2 samples of CS that had DM contents below $30.0 \%$, which is considered to be low, and one sample with a DM content of $42.9 \%$, which is considered moderately high, the CS samples analyzed in the current study ensiled at an adequate DM level and $\mathrm{pH}$ and lactic acid concentrations were also within the normally desired range (Kung and Shaver, 2001). High moisture corn chemical analyses were also considered normal.

The number of yeasts in silage at the time of opening often dictates the fate of silages during feed-out. For the present study, yeast counts varied from 5.4 to $6.3 \log _{10}$ cfu/g of silage, and according to Daniel et al. (1970) silages having a population in excess of $10^{5} \mathrm{cfu} / \mathrm{g}$ of DM are particularly prone to aerobic deterioration. Middelhoven (1998) also reported that silages with a large yeast population (e.g., $>1 \times 10^{5} \mathrm{cfu} / \mathrm{g}$ ) will be spoiled by these organisms upon exposure to air. Furthermore, feedback from the field suggests that producers often have problems when the numbers of yeasts are more than $1 \times 10^{6} \mathrm{cfu} / \mathrm{g}$ of silage (Kung, 2005). In regard to the population of molds, the number for the current study is within the normal range usually reported for these silages.

Many of the experiments characterizing the diversity of yeasts in CS have been conducted in Europe, making it difficult to relate their findings to conditions in the United States. A survey conducted by Middelhoven and Franzen (1986) reported that the yeast microbiota of 13 different CS was dominated by members of 2 genera: Candida and Saccharomyces. Middelhoven (1998) found that Candida milleri predominated during the first 2 wk of anaerobiosis and was accompanied by Candida holmii, C. lambica, and Candida krusei. After about $4 \mathrm{mo}$, the CS was subjected to aerobic deterioration, and the authors found a dramatic increase in yeast numbers due to growth of C. milleri, C. holmii, and Candida lambica. Middelhoven and van Baalen (1988) isolated several predominant species in CS including I. orientalis, Geotrichum candidum, P. anomala, and P. fermentans. Using a DNA sequence-based approach, May et al. (2001) reported that yeasts, including $P$. anomala, were the dominant fungi present 2 to $3 \mathrm{mo}$ after ensiling in CS grown in Canada from a single lo- 


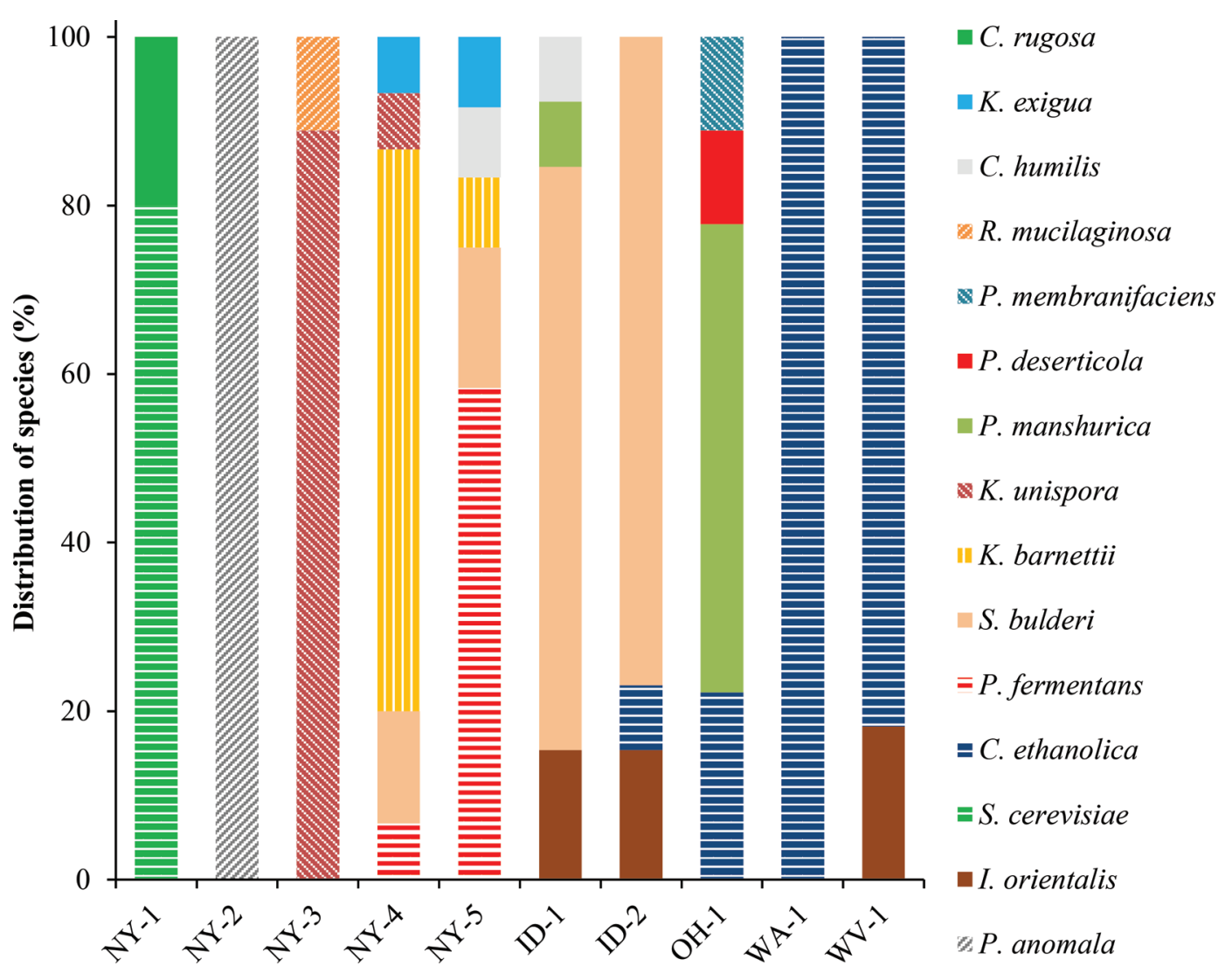

Sample identification

Figure 1. Distribution of yeasts (of genera Saccharomyces, Pichia, Rhodotorula, Naumovozyma, Kazachstania, and Issatchenkia) in corn silage samples collected from US dairy farms as determined by DNA analysis. Sample identification: the first 2 letters represent the state (New York, Idaho, Ohio, Washington, and West Virginia) and are followed by the farm number. Color version available online.

cation. In Italy, a recent study conducted by Dolci et al. (2011) showed that the dominant yeast species of CS after exposure to air, as observed from the DGGE profiles of fungal DNA and RNA, was Kazachstania exigua. Prior to the present study, apparently no studies were done characterizing the diversity of yeasts in CS from across the United States. Mansfield and Kuldau (2007) characterized yeasts in several CS exclusively from Pennsylvania. They reported that G. candidum was detected in $21 \%$ of the silage samples collected for 2 consecutive years on 12 farms. They also reported that Candida intermedia, Candida sake, Debaryomyces hansenii, I. orientalis, P. anomala, P. fermentans, and Pichia membranifaciens also occurred at relatively high frequency. In the study of Carvalho et al. (2016), I. orientalis was found in the highest frequency of CS isolates $(46 \%)$ in Brazil but it only represented $4.9 \%$ of the isolates in CS in our study. The presence of a high frequency of $C$. ethanolica in samples analyzed in the current study was not expected because this microor- ganism has usually not been identified in the microbial population of CS in past studies, although its presence was recently reported in CS in Brazil by Carvalho et al. (2016). In that study C. ethanolica was reported to be able to metabolize lactic acid. Candida ethanolica has also been reported in fermented pig feed composed of a cereal grain mix with wet wheat distillers grain (Olstorpe et al., 2010). Saccharomyces bulderi, found in the present study, was also isolated from CS by Middelhoven et al. (2000). This yeast species was reported to be related to Saccharomyces barnettii and Saccharomyces exiguus. The authors also reported that $S$. bulderi is characterized by rapid fermentation of galactose and failure to assimilate nonfermentable substrates such as ethanol and lactic acid. Kazachstania unispora, isolated from 2 of 10 CS samples in the current study, was also reported by $\mathrm{Lu}$ et al. (2004) as one of the dominant species of yeasts in aerobically deteriorating CS in Japan on the opening day and after $1,3,5$, and $7 \mathrm{~d}$ of exposure to air. 


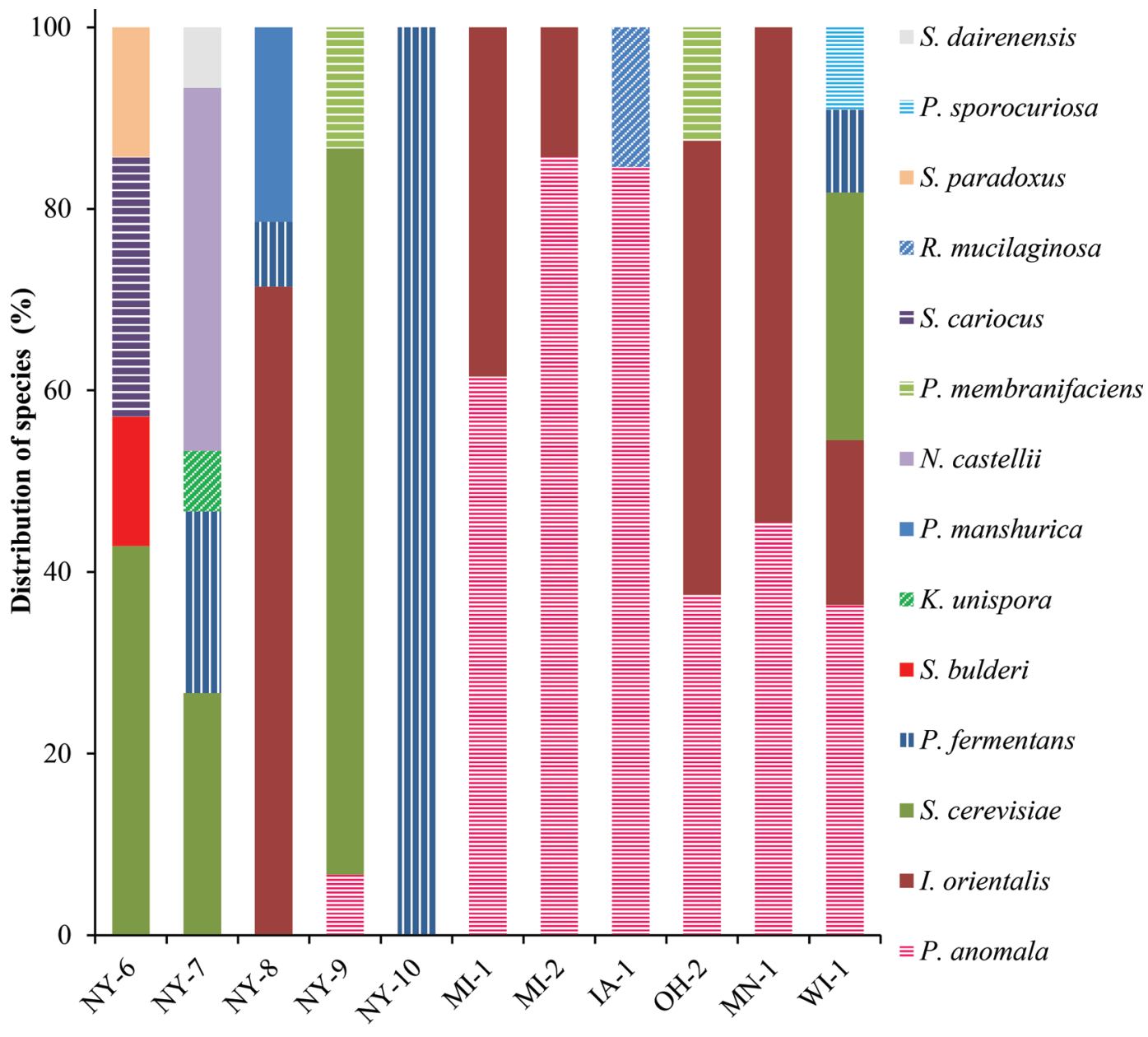

Sample identification

Figure 2. Distribution of yeasts (of genera Candida, Kazachstania, Rhodotorula, Pichia, Saccharomyces, and Issatchenkia) in high moisture corn samples collected from US dairy farms as determined by DNA analysis. Sample identification: the first 2 letters represent the state (New York, Michigan, Iowa, Ohio, Minnesota, and Wisconsin) and are followed by the farm number. Color version available online.

For HMC, Burmeister and Hartman (1966) reported that after the $12 \mathrm{~d}$ of storage, $P$. anomala and $I$. orientalis were the major species of yeasts and the results from our current study agree with those findings (Table

Table 3. Agreement among different methods used for the identification of yeasts isolated from silage samples

\begin{tabular}{lc}
\hline Methods used for identification $^{1}$ & \% agreement $^{2}$ \\
\hline ID 32C, FAME, and DNA & 16.6 \\
ID 32C and DNA & 41.1 \\
FAME and ID 32C & 14.4 \\
FAME and DNA & 2.2 \\
\hline
\end{tabular}

${ }^{1}$ ID $32 \mathrm{C}=$ physiological substrate profiling analysis using the API kit ID 32C (bioMérieux, Marcy-l'Etoile, France); DNA = sequencing of the internal transcribed spacer region of the DNA; FAME = fatty acid methyl ester analysis.

${ }^{2}$ Percentages of agreements among methods were calculated based on the analysis of 90 colonies that were randomly selected.
2). Several studies have reported $P$. anomala in other silages. For example, May et al. (2001) and Mansfield and Kuldau (2007) found this species in CS collected in the United States. This species was also detected in grass silage produced in Ireland (O'Brien et al., 2007, 2008) and in Japan ( $\mathrm{Li}$ and Nishino, 2011) and in sugar cane silage produced in Brazil (Ávila et al., 2010). In regard to the other 2 species that predominated in HMC, S. cerevisiae was one of the dominant species of yeasts isolated from aerobically deteriorating CS in Japan (Lu et al., 2004), whereas P. fermentans was detected in baled grass silages in Ireland (O'Brien et al., 2007, 2008) and in CS from farms located in various regions of Italy (Rossi and Dellaglio, 2007). All of these yeasts are ubiquitous species usually found in a wide range of silage types.

The general lack of agreement in identifying yeasts by FAME analysis when compared with PCR and sub- 
Table 4. Substrate utilization of isolates belonging to the most frequently identified yeast species

\begin{tabular}{|c|c|c|c|c|c|c|c|}
\hline Isolate number & Species name $^{1}$ & \multicolumn{6}{|c|}{ Substrate utilization ${ }^{2}$} \\
\hline 4 & Pichia anomala & + & + & + & + & + & + \\
\hline 35 & P. anomala & + & + & + & + & + & + \\
\hline 41 & P. anomala & + & + & + & + & + & + \\
\hline 107 & P. anomala & - & + & + & + & + & + \\
\hline 501 & P. anomala & + & + & + & + & + & + \\
\hline 505 & P. anomala & + & + & + & + & + & + \\
\hline 508 & P. anomala & + & + & + & + & + & + \\
\hline 6 & Issatchenkia orientalis & + & + & + & - & - & + \\
\hline 10 & I. orientalis & - & - & + & - & - & + \\
\hline 11 & I. orientalis & - & - & + & - & - & + \\
\hline 12 & I. orientalis & + & - & + & - & - & + \\
\hline 187 & S. cerevisiae & + & + & - & - & - & + \\
\hline 196 & S. cerevisiae & + & + & - & - & - & + \\
\hline 197 & S. cerevisiae & + & + & - & - & - & + \\
\hline 509 & S. cerevisiae & + & + & - & - & - & + \\
\hline 513 & S. cerevisiae & + & + & - & - & - & + \\
\hline
\end{tabular}

${ }^{1}$ Isolates were identified by DNA and substrate profile as the same microorganism.

${ }^{2}+=$ positive for utilization of the substrate; $-=$ negative for the utilization of the substrate.

strate profiling may be due the poor identification of yeasts by the former method because of the low number of fatty acids in the cell wall of yeasts. Rattray et al. (1975) reported that the low variability in the cellular fatty acid pool of yeasts may not provide a sufficient database for chemotaxonomy. Loureiro and Querol (1999) also reported that the use of fatty acid profiling as a biomarker has not been successfully used to type spoilage yeasts in the food industry due to the low variability of yeast fatty-acid composition. In contrast, in bacteria, more than 300 fatty acids and related compounds are found in their cell walls and both number and relative amounts of each appear to be unique among species, which allows for the use of this technique as a powerful tool in bacterial phylogeny (Sasser, 2001). In contrast, the ID32C has been used by several authors as a reference system for the identification of yeasts due to its extensive database and accuracy (Gutierrez et al., 1994; Fricker-Hidalgo et al., 1995, 1996).

The results of the substrate utilization analysis in the present study agree with the data available in the literature. Jonsson and Pahlow (1984) reported that $I$. orientalis can assimilate lactate, whereas $S$. cerevisiae can assimilate sugars but not lactate. Those authors also found that if anaerobic conditions were achieved and maintained in silage, fermentative, but non-lactate-assimilating $S$. cerevisiae prevailed, whereas if air penetrated into the silage during storage, lactate-assimilating yeasts of the genera Candida and Hansenula (= Pichia $)$ predominated. Middelhoven and van Baalen (1988) found that 3 strains of $P$. anomala isolated from CS were able to assimilate starch, dextrin, maltose, and lactic acid, whereas strains of $I$. orientalis were able to assimilate lactic acid, but failed to assimilate starch and maltose. Burmeister and Hartman (1966) also found that $P$. anomala and $I$. orientalis isolates from HMC silages were able to assimilate lactic acid.

\section{CONCLUSIONS}

The results of this study showed that identification of yeasts using the API kit ID 32C generally corresponded with identification using DNA analysis; however, identification using FAME analysis frequently produced disparate results. Based on DNA analysis, the types of yeasts found in CS and HMC sampled from several states in the United States varied due to type of feed and location. Pichia anomala and I. orientalis were found in 7 of 10 and 6 of 10 HMC samples, respectively. Pichia fermentans and S. cerevisiae were both found in 4 of 10 HMC samples. In contrast, C. ethanolica (4 of 11 samples) and C. bulderi (4 of 11 samples) were the yeasts most commonly identified in CS. More research is warranted to understand why species of yeasts vary 
from farm to farm and if this variability is related to issues with aerobic instability of silages. In addition, other factors such as level of DM, types of silos, use of additives, and silage density may affect yeasts in silages and these factors should also be considered in future studies.

\section{ACKNOWLEDGMENTS}

This study was partially funded by Elanco Animal Health Inc. (Greenfield, IN). The authors thank all the cooperators in the field for providing the silage samples used in this study. We also thank the staff of the Dairy Nutrition and Silage Fermentation Laboratory of the University of Delaware for their assistance with this study.

\section{REFERENCES}

Ávila, C. L., C. Bravo Martins, and R. Schwan. 2010. Identification and characterization of yeasts in sugarcane silages. J. Appl. Microbiol. 109:1677-1686.

Botha, A., and J. L. Kock. 1993. Application of fatty acid profiles in the identification of yeasts. Int. J. Food Microbiol. 19:39-51.

Buesching, W. J., K. Kurek, and G. D. Roberts. 1979. Evaluation of the modified API $20 \mathrm{C}$ system for identification of clinically important yeasts. J. Clin. Microbiol. 9:565-569.

Burmeister, H. R., and P. A. Hartman. 1966. Yeasts in ensiled highmoisture corn. Appl. Microbiol. 14:35-38.

Cai, J., I. N. Roberts, and M. D. Collins. 1996. Phylogenetic relationships among members of the ascomycetous yeast genera Brettanomyces, Debaryomyces, Dekkera, and Kluyveromyces deduced by small-subunit rRNA gene sequences. Int. J. Syst. Bacteriol. $46: 542-549$.

Carvalho, B. F., C. L. S. Avila, P. M. Kremper, L. R. Batista, M. N. Pereira, and R. F. Schwan. 2016. Occurrence of mycotoxins and yeasts and moulds identification in corn silages in tropical climate. J. Appl. Microbiol. 120:1181-1192.

Chang, H. C., S. N. Leaw, A. H. Huang, T. L. Wu, and T. C. Chang. 2001. Rapid identification of yeasts in positive blood cultures by a multiplex PCR method. J. Clin. Microbiol. 39:3466-3471.

Daniel, P., H. Honig, F. Weise, and E. Zimmer. 1970. Wirkung von Propionsäure bei der Grünfuttersilierung. Wirtschaflseigene Futter. 16:239-252.

Dolci, P., E. Tabacco, L. Cocolin, and G. Borreani. 2011. Microbial dynamics during aerobic exposure of corn silage stored under oxygen barrier or polyethylene films. Appl. Environ. Microbiol. 77:7499-7507.

Fricker-Hidalgo, H., B. Lebeau, P. Kervroedan, O. Faure, P. AmbroiseThomas, and R. Grillot. 1995. Auxacolor, a new commercial system for yeast identification: Evaluation of 182 strains comparatively with ID 32C. Ann. Biol. Clin. (Paris) 53:221-225.

Fricker-Hidalgo, H., O. Vandapel, M. A. Duchesne, M. A. Mazoyer, D. Monget, B. Lardy, B. Lebeau, J. Freney, P. Ambroise-Thomas, and R. Grillot. 1996. Comparison of the new API Candida system to the ID $32 \mathrm{C}$ system for identification of clinically important yeast species. J. Clin. Microbiol. 34:1846-1848.

Gutierrez, J., E. Martin, C. Lozano, J. Coronilla, and C. Nogales. 1994. Evaluation of the ATB 32C, automicrobic system and API 20C using clinical yeast isolates. Ann. Biol. Clin. (Paris) 52:443-446.

Heelan, J. S., E. Sotomayor, K. Coon, and J. B. D'Arezzo. 1998. Comparison of the Rapid Yeast Plus panel with the API20C yeast system for identification of clinically significant isolates of Candida species. J. Clin. Microbiol. 36:1443-1445.
Jonsson, A., and G. Pahlow. 1984. Systematic classification and biochemical characterization of yeasts growing in grass silage inoculated with Lactobacillus cultures. Anim. Res. Dev. 20:7-22.

Kung, L., Jr. 2005. Aerobic stability of silages. Accessed May 13, 2011. http://ag.udel.edu/anfs/ faculty/kung/ documents/05AerobicStability.pdf.

Kung, L., Jr., and R. Shaver. 2001. Interpretation and use of silage fermentation analysis reports. Focus on Forage. University of Wisconsin, Madison. 3:1-5.

Kung, L. Jr., A. C. Sheperd, A. M. Smagala, K. M. Endres, C. A. Bessett, N. K. Ranjit, and J. L. Glancey. 1998. The effect of preservatives based on propionic acid on the fermentation and aerobic stability of corn silage and a total mixed ration. J. Dairy Sci. $81: 1322-1330$

Kurtzman, C. P. 1992. rRNA Sequence comparisons for assessing phylogenetic relationships among yeasts. Int. J. Syst. Bacteriol. $42: 1-6$.

Lachance, M. A. 2006. Yeast biodiversity: How many and how much? Pages 1-9 in The Yeast Handbook: Biodiversity and Ecophysiology of Yeasts. C. Rosa and G. Peter, ed. Springer, Heidelberg, Germany.

Li, Y., and N. Nishino. 2011. Bacterial and fungal communities of wilted Italian ryegrass silage inoculated with and without Lactobacillus rhamnosus or Lactobacillus buchneri. Lett. Appl. Microbiol. $52: 314-321$

Loureiro, V., and A. Querol. 1999. The prevalence and control of spoilage yeasts in foods and beverages. Trends Food Sci. Technol. 10:356-365.

Lu, H. Z., Y. Cai, Z. W. Wu, J. H. Jia, and F. Y. Bai. 2004. Kazachstania aerobia sp. nov., an ascomycetous yeast species from aerobically deteriorating corn silage. Int. J. Syst. Evol. Microbiol. 54:2431-2435.

Luo, G., and T. G. Mitchell. 2002. Rapid identification of pathogenic fungi directly from cultures by using multiplex PCR. J. Clin. Microbiol. 40:2860-2865.

Mansfield, M. A., and G. Kuldau. 2007. Microbiological and molecular determination of mycobiota in fresh and ensiled maize silage. Mycologia 99:269-278.

May, L. A., B. Smiley, and M. G. Schmidt. 2001. Comparative denaturing gradient gel electrophoresis analysis of fungal communities associated with whole plant corn silage. Can. J. Microbiol. 47:829-841.

McDonald, P., A. R. Henderson, and S. J. E. Heron. 1991. The Biochemistry of Silage. 2nd ed. Chalcombe Publications, Marlow, UK.

Middelhoven, W. J. 1998. The yeast flora of maize silage. Food Technol. Biotechnol. 36:7-11.

Middelhoven, W. J., and M. M. Franzen. 1986. The yeast flora of ensiled whole crop maize. J. Sci. Food Agric. 37:855-861.

Middelhoven, W. J., C. P. Kurtzman, and A. Vaughan-Martini. 2000. Saccharomyces bulderi sp. nov., a yeast that ferments gluconolactone. Antonie van Leeuwenhoek 77:223-228.

Middelhoven, W. J., and A. H. M. van Baalen. 1988. Development of the yeast flora of whole-crop maize during ensiling and during subsequent aerobiosis. J. Sci. Food Agric. 42:199-207.

Moon, N. J., and L. O. Ely. 1979. Identification and properties of yeasts associated with the aerobic deterioration of wheat and alfalfa silages. Mycopathologia 69:153-156.

Muck, R. E., and J. T. Dickerson. 1988. Storage temperature effects on proteolysis in alfalfa silage. Trans. ASAE 31:1005-1009.

O'Brien, M., P. O'kiely, P. Forristal, and H. Fuller. 2008. Fungal contamination of big-bale grass silage on Irish farms: Predominant mould and yeast species and features of bales and silage. Grass Forage Sci. 63:121-137.

O'Brien, M., P. O'Kiely, P. D. Forristal, and H. T. Fuller. 2007. Quantification and identification of fungal propagules in well-managed baled grass silage and in normal on-farm produced bales. Anim. Feed Sci. Technol. 132:283-297.

Olstorpe, M., L. Axelsson, J. Schnürer, and V. Passoth. 2010. Effect of starter culture inoculation on feed hygiene and microbial population development in fermented pig feed composed of a ce- 
real grain mix with wet wheat distillers' grain. J. Appl. Microbiol. 108:129-138.

Pahlow, G., R. E. Muck, F. Driehuis, S. J. W. H. Oude Elferink, and S. F. Spoelstra. 2003. Microbiology of ensiling. Pages 31-93 in Silage Science and Technology. D. R. Buxton, R. E. Muck, and J. H. Harrison, ed. Am. Soc. Agron., Crop Sci. Soc. Am., Soil Sci. Soc. Am., Madison, WI.

Querol, A., and D. Ramòn. 1996. The application of molecular techniques in wine microbiology. Trends Food Sci. Technol. 7:73-78.

Rattray, J. B. M., A. Schibeci, and D. K. Kidby. 1975. Lipids of yeasts. Bacteriol. Rev. 39:197-231.

Rossi, F., and F. Dellaglio. 2007. Quality of silages from Italian farms as attested by number and identity of microbial indicators. J. Appl. Microbiol. 103:1707-1715.

Sasser, M. 1991. MIS whole fatty acid analysis by gas chromatography. Microbial ID Inc., Newark, DE.

Sasser, M. 2001. Identification of bacteria by gas chromatography of cellular fatty acids. MIDI Technical Note 101. Microbial ID Inc., Newark, DE.
White, T., T. Bruns, S. Lee, and J. Taylor. 1990. Amplification and direct sequencing of fungal ribosomal RNA genes for phylogenetics. Pages 315-322 in PCR Protocols: A Guide to Methods and Applications. M. A. Innis, D. H. Gelfand, J. J. Sninisky, and T. J. White, ed. Academic Press, San Diego, CA.

Willemsen, M., J. Breynaert, and S. Lauwers. 1997. Comparison of Auxacolor with API 20C Aux in yeast identification. Clin. Microbiol. Infect. 3:369-375.

Woolford, M. K. 1990. The detrimental effects of air on silage. J. Appl. Bacteriol. 68:101-116.

Yamada, Y., M. Matsuda, K. Maeda, and K. Mikata. 1994. The phylogenetic relationships of species of the genus Dekkera van der Walt based on the partial sequences of $18 \mathrm{~S}$ and $26 \mathrm{~S}$ ribosomal RNAs (Saccharomycetaceae). Biosci. Biotechnol. Biochem. 58:1803-1808. 